\title{
EDITORIAL
}

\section{Focus on infection}

\author{
Ignacio Martin-Loeches ${ }^{1,2^{*}}$, Garyphallia Poulakou ${ }^{3}$ and Saad Nseir ${ }^{4}$
}

C 2019 Springer-Verlag GmbH Germany, part of Springer Nature

Management of infection in Intensive-Care Unit (ICU) has advanced a lot over the last decade. Implementation of antibiotic stewardship programs (ASP) and better prevention strategies are among the most recognized contributors to the current development. In this manuscript, we aim to provide an overview of the most relevant last year's publications that we consider will influence daily clinical practice.

Antimicrobial resistance (AMR), particularly among Gram-negative pathogens, is, with no doubt, the more worrying problem in the treatment of infections in the world. In a multicentric, worldwide study, sepsis patients had identified pathogens in $69.6 \%$, two-thirds of them were Gram-negative bacteria which predominated in abdominal, urinary, and respiratory infections over Gram-positive isolates [1]. Due to the alarming globalization of AMR, the European Society of Intensive Care Medicine (ESICM), the European Society of Microbiology and Infectious Diseases (ESCMID), and the World Alliance Against Antimicrobial Resistance (WAAAR), provided through a task force recommendations to reduce AMR development in critically ill patients, by gathering efforts to improve scientific research and ultimately provide better approaches to the treatment of AMR infections [2]. Among multidrug-resistant (MDR) pathogens, extended-spectrum $\beta$-lactamase-producing Enterobacteriaceae (ESBLE) stand out as an important threat. A French study analyzing over 300 ESBLE carriers found that carriage was a strong carbapenem empirical consumption driver, but mostly reflected non-infectious events [3]. MDR Klebsiella spp. is another strong driver of broad-spectrum prescriptions, for which an Italian group aimed to develop a prognostic model for mortality

\footnotetext{
*Correspondence: drmartinloeches@gmail.com

${ }^{1}$ Department of Intensive Care Medicine, Multidisciplinary Intensive Care Research Organization (MICRO), St. James's Hospital, St James Street, Dublin 8, Dublin, Ireland

Full author information is available at the end of the article
}

among ICU admitted patients [4]. The study showed a major association of appropriateness of empirical antibiotic therapy and hospital mortality based on the risk-ofdeath, being very influential if the risk was high. Among Gram-positives, a major role was shown for Enterococcus spp. in a US study investigating the gastrointestinal microbiome in critically ill patients; vancomycin-resistant Enterococcus (VRE) colonization and Enterococcus spp. domination were both associated with death or all-cause infection [5]. Rectal carriage of Gram-negative pathogens such as Escherichia coli, Pseudomonas spp., and Klebsiella spp. at ICU admission, was associated with subsequent infection with the same organism, whilst Clostridium difficile and VRE were associated with subsequent Enterococcus infection. Resistance in fungal infections is a matter of a current concern. Candida auris has emerged as a new nosocomial threat due to resistance to antifungals; a recent ICU outbreak from US linked its transmission with reusable equipment, showing a worrisome persistence in the environment of healthcare settings [6].

Reliable tools assessing host factors and immune response have been a continuous demand in clinical practice. Three cell surface markers associated with immune cell dysfunction [neutrophil CD88, monocyte human leucocyte antigen-DR (HLA-DR), and percentage of regulatory T cells (Tregs)] predicted secondary infections using flow cytometry raising hopes for guidance of co-adjuvant therapy for sepsis [7]. Organ failure is an important determinant of the use of co-adjuvant therapy. A multicenter study found that the protective association of endogenous immunoglobulins (specially IgM) against sepsis mortality was restricted to patients with moderate organ failure [8]. When using this information in severe Community-Acquired Pneumonia (CAP), a randomized, placebo-controlled, double-blind, multicenter, phase II trial of polyclonal antibody preparation found benefit in mortality in patients with low $\operatorname{IgM}(\leq 0.8 \mathrm{~g} / \mathrm{L})$ and a high level of inflammation (C-reactive protein $\geq 70 \mathrm{mg} / \mathrm{L}$ ) [9].

\section{Springer}


Influenza has been predominating among viral causes of CAP over the last previous years during the winter season, with an increased risk of co-infection reported among immunocompetent and immunosuppressed patients [10]. A retrospective multicenter cohort study of adult patients with severe influenza admitted to ICUs in Belgium and The Netherlands from 2009 to 2016 [11] showed that one out of five patients were diagnosed with Invasive pulmonary aspergillosis (IPA). Influenza was identified as an independent risk factor for IPA and associated mortality was reported at $51 \%$. Classically, IPA has been a disease of severely immunocompromised patients such as neutropenic patients and organ transplant recipients. Additional risk factors, such as corticosteroid treatment and chronic obstructive pulmonary disease, have received increasing attention. In a multicentric study of almost 2000 patients with primary influenza pneumonia, of whom one-third received steroids, propensity score analysis showed that corticosteroids were associated with increased ICU mortality [12]. The findings argue against corticosteroid use in documented influenza pneumonia.

Regarding prevention, four major studies made important contributions in this area. First, a manuscript from Switzerland showed that the implementation of a multifaceted program was associated with decreased rates of VAP. After an initial decrease by $42 \%$ with an eightelement bundle (hand hygiene, head-of-bed elevation, oral care with chlorhexidine, endotracheal tube cuff pressure $\geq 25 \mathrm{~cm} \mathrm{H}_{2} \mathrm{O}$, sedation holds, ventilation weaning, active mobilization, and subglottic secretion suctioning), a further reduction by $70 \%$ from baseline rates was observed, with the addition of selective oral decontamination (SOD) [13]. Second, a French randomized double-blind placebo-controlled study investigating the role of oropharyngeal and nasopharyngeal decontamination with chlorhexidine in patients undergoing lung resection for cancer, could not demonstrate any benefit in decreasing the risk of respiratory infections, mechanical ventilation requirements, or postoperative antibiotic utilization [14]. A third study, conducted in Europe over 25,348 patients, focused on the reduction of central venous catheter-related bloodstream infections (CRBSI), as a means to relieve an avoidable burden of the morbidity and mortality associated with hospital BSIs. Using a large stepped-wedge cluster randomized-controlled multicenter intervention design, it was able to demonstrate that basic measures such as central venous catheter insertion strategy and a hand hygiene improvement strategy decreased CRBSI rates [15]. And finally, a large study with over 60,000 patients who were followed for a median of 14.8 years with indices of iron deficiency identified those with low serum iron and transferrin saturation
(Tsat) and high total iron-binding capacity (TIBC), as being at a higher bloodstream infections risk [16].

Infection in critically ill patients is a topic of huge clinical concern attracting considerable research. Whilst viral infections, prevention, immune response, and microbiome were areas of important developments last year, a deep collaboration among research groups and countries in the following years is key to ensure the implementation of the recent discoveries and progress to broadening research perspectives.

\section{Author details \\ ${ }^{1}$ Department of Intensive Care Medicine, Multidisciplinary Intensive Care Research Organization (MICRO), St. James's Hospital, St James Street, Dublin 8, Dublin, Ireland. ${ }^{2}$ Hospital Clinic, IDIBAPS, Universidad de Barcelona, Ciberes, Barcelona, Spain. ${ }^{3}$ 3rd Department of Medicine, Medical School, Sotiria General Hospital of Athens, National and Kapodistrian University of Athens, Athens, Greece. ${ }^{4}$ Department of Intensive Care Medicine, Critical Care Center, CHU of Lille, 59000 Lille, France.}

\section{Compliance with ethical standards}

\section{Conflicts of interest}

Dr Martin-Loeches reports personal fees from MSD and Gilead. Dr. Poulakou reports personal fees and non-financial support from Merck, grants, personal fees, and non-financial support from Pfizer. Dr. Nseir reports personal fees from Pfizer, Gilead, Biomérieux, and MSD.

\section{Publisher's Note}

Springer Nature remains neutral with regard to jurisdictional claims in published maps and institutional affiliations.

Received: 20 May 2019 Accepted: 13 June 2019

Published online: 18 June 2019

\section{References}

1. Sakr Y, Jaschinski U, Wittebole $X$ et al (2018) Sepsis in intensive care unit patients: worldwide data from the intensive care over nations audit. Open forum Infect Dis 5:ofy313. https://doi.org/10.1093/ofid/ofy313

2. De Waele JJ, Akova M, Antonelli M et al (2018) Antimicrobial resistance and antibiotic stewardship programs in the ICU: insistence and persistence in the fight against resistance. A position statement from ESICM/ ESCMID/WAAAR round table on multi-drug resistance. Intensive Care Med 44:189-196. https://doi.org/10.1007/s00134-017-5036-1

3. Barbier F, Bailly S, Schwebel C et al (2018) Infection-related ventilatorassociated complications in ICU patients colonised with extended-spectrum $\beta$-lactamase-producing Enterobacteriaceae. Intensive Care Med 44:616-626. https://doi.org/10.1007/s00134-018-5154-4

4. Bertolini G, Nattino G, Tascini C et al (2018) Mortality attributable to different Klebsiella susceptibility patterns and to the coverage of empirical antibiotic therapy: a cohort study on patients admitted to the ICU with infection. Intensive Care Med 44:1709-1719. https://doi.org/10.1007/ s00134-018-5360-0

5. Freedberg DE, Zhou MJ, Cohen ME et al (2018) Pathogen colonization of the gastrointestinal microbiome at intensive care unit admission and risk for subsequent death or infection. Intensive Care Med 44:1203-1211. https://doi.org/10.1007/s00134-018-5268-8

6. Eyre DW, Sheppard AE, Madder H et al (2018) A Candida auris outbreak and its control in an intensive care setting. N Engl J Med 379:1322-1331. https://doi.org/10.1056/nejmoa1714373

7. Conway Morris A, Datta D, Shankar-Hari M et al (2018) Cell-surface signatures of immune dysfunction risk-stratify critically ill patients: INFECT 
study. Intensive Care Med 44:627-635. https://doi.org/10.1007/s0013 4-018-5247-0

8. Martin-Loeches I, Muriel-Bombín A, Ferrer R et al (2017) The protective association of endogenous immunoglobulins against sepsis mortality is restricted to patients with moderate organ failure. Ann Intensive Care 7:44. https://doi.org/10.1186/s13613-017-0268-3

9. Welte T, Dellinger RP, Ebelt H et al (2018) Efficacy and safety of trimodulin, a novel polyclonal antibody preparation, in patients with severe community-acquired pneumonia: a randomized, placebo-controlled, double-blind, multicenter, phase II trial (CIGMA study). Intensive Care Med 44:438-448. https://doi.org/10.1007/s00134-018-5143-7

10. Martin-Loeches I, Schultz JM, Vincent J-L et al (2017) Increased incidence of co-infection in critically ill patients with influenza. Intensive Care Med. https://doi.org/10.1007/s00134-016-4578-y

11. Schauwvlieghe AFAD, Rijnders BJA, Philips N et al (2018) Invasive aspergillosis in patients admitted to the intensive care unit with severe influenza: a retrospective cohort study. Lancet Respir Med 6:782-792. https://doi. org/10.1016/s2213-2600(18)30274-1

12. Moreno G, Rodríguez A, Reyes LF et al (2018) Corticosteroid treatment in critically ill patients with severe influenza pneumonia: a propensity score matching study. Intensive Care Med 44:1470-1482. https://doi. org/10.1007/s00134-018-5332-4

13. Landelle C, Nocquet Boyer V, Abbas M et al (2018) Impact of a multifaceted prevention program on ventilator-associated pneumonia including selective oropharyngeal decontamination. Intensive Care Med 44:1777-1786. https://doi.org/10.1007/s00134-018-5227-4

14. D'Journo XB, Falcoz P-E, Alifano M et al (2018) Oropharyngeal and nasopharyngeal decontamination with chlorhexidine gluconate in lung cancer surgery: a randomized clinical trial. Intensive Care Med 44:578-587. https://doi.org/10.1007/s00134-018-5156-2

15. van der Kooi T, Sax H, Pittet $D$ et al (2018) Prevention of hospital infections by intervention and training (PROHIBIT): results of a pan-European cluster-randomized multicentre study to reduce central venous catheterrelated bloodstream infections. Intensive Care Med 44:48-60. https://doi. org/10.1007/s00134-017-5007-6

16. Mohus RM, Paulsen J, Gustad L et al (2018) Association of iron status with the risk of bloodstream infections: results from the prospective population-based HUNT Study in Norway. Intensive Care Med 44:1276-1283. https://doi.org/10.1007/s00134-018-5320-8 